\title{
A dificuldade de consolidação dos circuitos turísticos de Minas Gerais (Brasil): uma análise a partir do perfil dos seus gestores
}

\section{The difficulty of consolidation of Minas Gerais (Brazil) tourist circuits: an analysis from their managers' profile}

\author{
Jean Max Tavares (TAVARES, J. M.) ${ }^{*}$ \\ Jordânia Regina Mariano Batista (BATISTA, J. R. M.) ${ }^{* *}$
}

\begin{abstract}
RESUMO - Desde 2003, o Estado de Minas Gerais, Brasil, já reconheceu e certificou mais de 40 circuitos turísticos. Porém, muitos deles possuem dificuldade de atrair turistas e de se organizar administrativamente, apesar de, por lei, terem que possuir um gestor Bacharel em Turismo, responsável por exercer funções que envolvem diferentes áreas do conhecimento. Este artigo buscou entender as razões dessas dificuldades a partir do perfil dos gestores dos circuitos da região central do Estado. Para tanto, foram enviados questionários a gestores que atuam nessa região, a partir dos quais verificou-se que, embora todos os respondentes possuam curso superior em Turismo e experiência anterior no setor público, mais da metade recebe até três salários mínimos. A maioria não recebeu nenhum treinamento para a função e aponta como principais dificuldades a falta de apoio financeiro, político e de infraestrutura.
\end{abstract}

Palavras-chaves: Gestor; Circuitos; Minas Gerais.

ABSTRACT - Since 2003, Minas Gerais, Brazil, has recognized and certified more than 40 tourist circuits. However, a lot of them have difficulty in attracting tourists as well as organizing themselves administratively, in spite of having, by law, a Bachelor in Tourism as a manager, who is responsible for functions which involve different areas of knowledge. This paper tried to understand the reasons for these difficulties using these areas managers' profile. For this proposal, questionnaires were sent to the managers who work in this region. It was found that, despite all of them have a degree in tourism and previous experience in the public sector, more than a half receives till three Brazilian minimum salaries. Most of them did not receive any training to the function and points out the lack financial and political support and infrastructure as their main difficulties.

Key words: Manager; Tourist Circuits; Minas Gerais (Brazil).

\footnotetext{
" Graduação em Economia pela Pontifícia Universidade Católica de Minas Gerais (PUC Minas), Mestrado em Economia pela Universidade Federal do Ceará (UFC), Doutorado em Economia pela Universidade Federal do Rio Grande do Sul (UFRGS) e Pós-doutorado em Economia (Área: Turismo) na Universidade Nova de Lisboa (Portugal). Professor da Pontifícia Universidade Católica de Minas Gerais (PUC Minas). Endereço para correspondência: Av. Dom José Gaspar, 500, Bairro Dom Cabral. CEP 30.535-901 - Belo Horizonte - Minas Gerais (Brasil). Telefone para contato (31) 3439-5244. E-mail: jeanpucminas@uol.com.br

** Graduação em Turismo (Bacharelado) pela Pontifícia Universidade Católica de Minas Gerais (PUC Minas). Endereço para correspondência: Rua Josino Rodrigues, 48 a - Várzea. CEP: 33400-000 - Lagoa Santa - Minas Gerais (Brasil). Telefone para contato: (31) 3681-0711. E-mail: jomariano@ hotmail.com
} 


\section{INTRODUÇÃO}

É notória a importância que a atividade turística exerce em muitas economias. A capacidade de geração de emprego e renda, de atração de novos investimentos e de aumentar a arrecadação pública são alguns dos desdobramentos do turismo em uma região, embora aspectos negativos tais como congestionamentos, inflação e poluição também sejam identificados como possíveis consequências dessa atividade.

Embora não deva ser atribuída ao turismo toda a responsabilidade de promover o crescimento e o desenvolvimento regional, principalmente em pequenos e médios municípios, a atividade turística pode contribuir significativamente para tal propósito. E uma das condições para isto é a constituição de um produto turístico agregado que incentive o turista a aumentar seu período de permanência e seus gastos numa região.

Isto porque, via de regra, uma única atratividade turística pode não ser capaz de fazer um visitante (que não pernoita na região turística) se tornar um turista - passando 24 horas ou mais fora de sua residência, com pernoite - o que diminui os efeitos multiplicadores sobre uma região por não usufruírem, a contento, dos equipamentos turísticos existentes. Logo, se mais atratividades localizadas em um conjunto de regiões contíguas - aqui denominadas de circuitos turísticos (CT) - forem "agrupadas" como um "único destino", aumentam-se as chances do turismo se desenvolver na proporção que se espera dele, com todos os benefícios que o mesmo traz consigo.

Em sintonia com a política nacional de turismo, que defende a descentralização da gestão do setor, o Estado de Minas Gerais estimulou a criação e concedeu o reconhecimento oficial aos CT's de seu território. O propósito do governo mineiro foi "estruturar a atividade turística municipal e regional, buscando atrair mais turistas a determinada região, bem como estimular sua permanência ali por um tempo maior e [...] movimentar o comércio e os serviços turísticos locais" (EMMENDOERFER, 2008, p. 2).

Como a forma de gestão - via circuitos "independentes" do setor público - é pioneira no país, e por Minas Gerais ter mais de 850 municípios, totalizando 19.159.260 habitantes (IBGE, 2010) - compreendendo um território maior que o da França, o cenário do setor no Estado vem sendo bastante discutido nos últimos anos (SANTOS, 
2004; BOLSON, 2006; GOMES et al. 2006; GOMES et al. 2008; DOMINGOS e RIBEIRO, 2008; EMMENDOERFER, 2008).

Por exemplo, em pesquisa feita por GOMES et al. (2008) junto aos gestores de CT’s no Estado, a falta de conhecimento sobre turismo pela população local e a escassez de mão de obra qualificada foram apontadas como dois importantes obstáculos. Outra constatação importante em relação a fragilidade do modelo de gestão de CT's é apontada por Domingos e Ribeiro (2008, p. 3), segundo os quais “[...] apenas a vontade política, a proximidade dos municípios e a existência de atrativos turísticos não são suficientes para transformar uma região geográfica em uma região turística [...]".

Como o gestor deve ser Bacharel em Turismo - exigência do Governo de Minas Gerais para o reconhecimento do CT, via Decreto-Lei 43.321, de 08 de maio de 2003 (MINAS GERAIS, 2003) - e está em contato direito com os agentes locais ligados ao turismo e com a Secretaria de Turismo do Estado, variáveis como experiência profissional, formação acadêmica, treinamento e remuneração podem impactar diretamente na recuperação e consolidação dos CT's e do próprio desenvolvimento da atividade turística regional. Sua importância é destacada nesse Decreto-Lei, o qual reserva a percepção de remuneração apenas ao gestor do circuito, excluindo, por exemplo, o presidente do circuito dessa possibilidade.

Portanto, este artigo tem como objetivo identificar o perfil desses gestores e verificar se existe alguma relação entre o mesmo e a dificuldade de consolidação de grande parte dos CT's de Minas Gerais. Para isto, foram selecionados os gestores de 11 CT's localizados na região central de Minas Gerais, sendo a razão da escolha desses circuitos e a metodologia empregada descritas mais adiante.

\section{REFERENCIAL TEÓRICO}

Tem sido cada vez maior a competição entre os destinos turísticos ao redor do mundo, exigindo maior organização, capacitação e profissionalismo de todas as instituições e pessoas ligadas ao turismo. De forma mais específica, variáveis como infraestrutura, preços, qualidade das atrações turísticas, condições do meio-ambiente, estratégias de administração das regiões turísticas, papel da tecnologia da informação no 
setor e recursos humanos qualificados têm recebido a atenção de vários pesquisadores (HUSELID, 1995; PÉREZ, 1999; SHELDON, 1997; HARRISON e ENZ, 2005; OLSEN, 2004; SILVA e FABRIS, 2007).

Em relação aos recursos humanos em particular, o papel daqueles que estão na linha de frente da atividade turística e também daqueles que o coordenam são de suma importância para a satisfação do turista, da comunidade que abriga o destino turístico e do setor público. Quanto aos gestores responsáveis pela administração dessas regiões, esses devem receber atenção especial, tais como a participação em programas de treinamento, planos de carreira, estímulo à produtividade e redução da rotatividade (SIMON e HINKIN, 2001; CHO et al. 2006).

Outro aspecto importante ligado aos recursos humanos que atuam no setor turístico é que esses geralmente possuem estreita relação com o poder público, seja por meio de leis, obtenção de verbas, programas de certificação, treinamento e apoio político. Esse último não é sempre possível, visto que interesses partidários podem ocasionar conflito de interesses, dificultando a comunicação entre o gestor e o poder público, conforme afirma LLOYD (2000).

As questões acima mencionadas são ainda mais sensíveis quando se trata da formação e gestão de CT’s (PÉREZ, 1999). Isto porque, segundo Santos (2004, p. 29), um CT "compreende um conjunto de municípios com relativa proximidade em determinada área geográfica, caracterizado pela predominância de certos elementos da cultura, da história e da natureza, com possibilidades de atrair e seduzir turistas".

Isso significa que o gestor do CT deverá conviver com um ambiente marcado por interesses comuns e divergentes de vários municípios (pelo menos cinco, por força do Decreto-Lei), os quais constituem o destino turístico, exigindo-lhe várias competências e habilidades. Segundo Biz e Ceretta (2008, p. 412), a importância do gestor para o circuito turístico:

[...] é demonstrada por, ao tomar uma decisão [...] está definindo qual o caminho que o destino turístico irá percorrer ao longo de um tempo determinado. Em um mercado altamente competitivo, uma tomada de decisão não pertinente poderá ocasionar impactos ao seu desenvolvimento econômico, social, cultural e ecológico.

Esse cenário corrobora os resultados de uma pesquisa feita por Breiter e Clements (1996) para se avaliar a importância de 20 habilidades relativas aos seus 
gestores junto a empresas do setor turístico dos Estados Unidos. Nessa pesquisa, verificou-se que a relação humana tem posição proeminente (liderança, por exemplo, ocupando o primeiro lugar como habilidade mais importante, seguida por capacidade de comunicação). Porém, habilidades tais como promoção turística, gestão de habitação, informática, planejamento estratégico e direito turístico estão entre os de menor peso.

Quanto às características do gestor do circuito, Emmendoerfer et al. (2007, p. 11) afirmam que este deve ter "perfil de profissional do turismo, empreendedor, comunicativo, com espírito de liderança e carisma, devendo residir na região que abrange o circuito para lidar com as diferentes posições dos participantes do circuito $[\ldots] "$.

Além disso, o gestor deverá instalar e coordenar um centro de informações turísticas em um dos municípios do CT, em local de fácil acesso e com boa infraestrutura, o que demanda conhecimentos de marketing, administração de recursos humanos, logística e tecnologia da informação, dentre outras áreas. Ressalta-se que a existência desse centro de informações é muito importante para o turista (FASENMAIER, 1994) e, em Minas Gerais, constitui-se em uma das exigências do Governo do Estado para a certificação do CT. Para Emmendoerfer et al. (2007, p. 11) "o gestor, além de ter outras atribuições deve atender às solicitações do conselho regional criando oportunidades de negócios e arrecadação de recursos".

Contudo, apenas o cargo de gestor é remunerado no $\mathrm{CT}$, o que é feito com recursos gerados pela própria associação gestora do mesmo. Os demais, tais como presidente e secretários, são voluntários, fazendo com que tenham uma segunda ocupação e, assim, não dêem a merecida importância, não se responsabilizem ou não valorizem devidamente a organização do circuito.

Por fim, ressalta-se que, embora não seja formalmente uma das incumbências de um gestor de circuitos turísticos, a importância da organização de redes nas regiões envolvidas exige, naturalmente, o seu envolvimento direto nesse processo. Dentre outros objetivos, a organização de redes busca se constituir numa estratégia para melhor desenvolver e comercializar o produto turístico (SEBEN e SILVA, 2002; SILVA, 2004; BENI, 2003).

No caso do trabalho a ser desempenhado pelos gestores de circuitos turísticos, a formação de redes, que promova a troca de informações, de experiências e a tomada de 
decisões em conjunto, pode ser um elemento que contribui significativamente para a realização do mesmo com sucesso.

Como existem mais de 40 circuitos turísticos certificados em Minas Gerais e, portanto, o mesmo número de gestores, é possível incentivar e promover a cooperação entre eles, mesmo reconhecendo que os circuitos competem entre si. Segundo Tálamo (2008, p. 34), citado por Czajkowski e Cunha (2010) ${ }^{1}$, “os atores da rede de cooperação estabelecem elos de ligação entre si e esta ligação é que define a estrutura em forma de rede e sua taxonomia".

Segundo SILVA (2004, p. 268), as redes de empresas são “organizações assentadas na confiança entre as partes e orientadas para objetivos muito concretos". Em termos de turismo, essas empresas podem ser entendidas como os empreendimentos que pertencem ao trade - hotelaria, alimentação, entretenimento, locação de automóveis, dentre outros - ou, de acordo com esse trabalho, as próprias associações gestoras do turismo.

Mais que uma iniciativa, se organizar e trabalhar em rede deve fazer parte de uma cultura, a qual deve ser fortalecida com o passar do tempo e com a obtenção de resultados. Em Minas Gerais, no início do processo de formação dos circuitos turísticos, foram realizadas mais de 50 oficinas, nas quais o representante de cada município podia envolver-se com os demais, com a participação direta de mais de 3 (três) mil pessoas (SETUR, 2010). Portanto, a formação de oficinas já visava contribuir para a "formação de uma cultura" de cooperação.

Mas esse objetivo não é fácil de ser conquistado, fazendo-se necessárias várias ações continuadas, consolidando essa estratégia de gestão. Quanto a essa dificuldade, Emmendoerfer (2008, p. 232) afirma que essas “oficinas também permitiram detectar que os agentes envolvidos no turismo dos municípios e circuitos não possuem sistemas de gestão que articulem a cadeia de turismo e coordenem seu funcionamento".

As ações supracitadas remetem à forma como a governança está inserida no desenvolvimento da atividade turística. Para Löffler (2001, p. 212), a governança se apresenta como "uma nova geração de reformas administrativas e de Estado, que têm como objeto a ação conjunta, levada a efeito de forma eficaz, transparente e

\footnotetext{
${ }^{1}$ TÁLAMO, J. R. Formação e gestão de redes de cooperação empresarial. 2008. 233f. Tese (Doutorado em Engenharia de Produção) - Setor de Ciências Exatas, Escola Politécnica da Universidade de São Paulo, São Paulo, 2008.
} 
compartilhada" (BARBARÁ et al., 2007, p. 4). Essa definição enquadra-se nos objetivos da Secretaria de Estado de Turismo de Minas Gerais, que descentralizou a gestão do turismo a partir do reconhecimento e certificação dos circuitos turísticos do Estado, dotando-os de mais autonomia e de responsabilidades.

Segundo Barbará et al. (2007, p. 5), “a governança constitui-se em um modelo de gestão onde atores locais e regionais promovem juntos determinada ação". Como um circuito turístico em Minas Gerais é composto por vários municípios (mínimo de 5), as decisões tomadas são, geralmente, em conjunto, refletindo, pelo menos de forma superficial, em uma instância de governança regional.

Diante de tantas demandas, uma boa formação acadêmica é exigida do profissional que deseja atuar na gestão do setor turístico, o que demanda instituições de ensino especializadas e dotadas de capital humano qualificado. Embora se possa supor que os cursos de graduação e de pós-graduação de Turismo (e Hotelaria) no Brasil estejam conseguindo suprir a demanda por mão de obra a contento, dados da CAPES (Coordenação de Aperfeiçoamento de Pessoal de Nível Superior) apontam que o país possui somente 8 (oito) cursos de pós-graduação strictu senso, sendo apenas 1 (um) em nível de doutorado (CAPES, 2012), o que é pouco, considerando-se as dimensões do Brasil e sua clara vocação para o turismo.

De qualquer forma, entende-se que os setores público e privado podem contribuir mais para a valorização do profissional de Turismo e das instituições de ensino a partir da exigência de pessoal qualificado em suas atividades, priorizando critérios técnicos, bem como por meio de uma política salarial condizente com sua formação.

A questão problemática desse cenário marcado por novas exigências é que o turismo ainda parece ser tratado com pouca técnica e com muita informalidade por vários de seus agentes, seja por cultura, falta de conhecimentos ou devido à insuficiência de recursos. Além disso, no início de 2012, foi sancionada a Lei $12.591^{2}$ que apenas descreveu as atividades que o turismólogo está apto a exercer, não exigindo diploma e registro no órgão competente para exercer a profissão (GLOBO, 2012).

Como resultados desse tratamento ao setor, aparecem a deterioração das condições de trabalho dos profissionais ligados à atividade, salários inferiores aos

\footnotetext{
${ }^{2}$ Lei $\mathrm{N}^{\circ} 12.591$, de 18 de janeiro de 2012. Reconhece a profissão de Turismólogo e disciplina o seu exercício. Disponível em: 〈http://www.planalto.gov.br/ccivil_03/_ato2011-2014/2012/lei/112591.htm〉.
} 
oferecidos em áreas do mercado que exigem qualificação similar e baixa autoestima. Esse cenário pode resultar em mau atendimento ao turista, má gestão dos recursos públicos e privados direcionados ao setor e insatisfação profissional. Medaglia e Silveira (2010), por exemplo, realizaram um estudo junto a 215 egressos de cursos superiores em Turismo no Estado do Paraná, Brasil, o qual apontou que 56\% dos entrevistados recebiam até $\mathrm{R} \$ 1.500,00$ mensais.

Além disso, as principais funções públicas pertinentes ao turismo normalmente são feitas por profissionais de carreira política e não com domínio e formação técnica da área, o que não só desprestigia a atividade como desestimula a atração de novos estudantes. Por exemplo, em pesquisa realizada por Côrso et al. (2011), em sete municípios pertencentes a Rota da Amizade, no Estado de Santa Catarina, Brasil, apenas 1 deles possuía curso superior em Turismo e Administração Hoteleira.

Portanto, uma vez descrito o cenário envolvendo os profissionais ligados à administração do turismo enquanto setor de atividade econômica, e tendo por enfoque o o objetivo de identificar o perfil dos gestores dos circuitos turísticos da região central de Minas Gerais, foi utilizada a metodologia a seguir.

\section{METODOLOGIA}

A amostra da pesquisa é composta pelos gestores de 11 CT's localizados na região central de Minas Gerais, conforme quadro 1 e foi selecionada em virtude destes CT's possuírem as principais características e atrativos do Estado, tais como paisagens, grutas, aspectos culturais, religiosos e artísticos, esportes náuticos, vida rural, recursos minerais, englobando os vários tipos de turismo existentes. Os presidentes dos circuitos não foram entrevistados, já que não possuem essa atividade como a principal em razão da mesma não ser remunerada, distanciando-os da realidade administrativa do circuito e acentuando a importância do gestor.

Além disso, estes 11 CT's representam 102 municípios de Minas Gerais, os quais, em sua maioria, dependem muito das transferências de recursos governamentais para estimular a economia, e possuem população inferior a 40 mil habitantes (IBGE, 
2010), salvo algumas exceções, como, por exemplo, Sete Lagoas, Lagoa Santa e Ouro

Preto (quadro 1).

QUADRO 1 - CIRCUITOS TURÍSTICOS CORAÇÃO DAS GERAIS E SUAS UNIDADES TURÍSTICAS.

\begin{tabular}{|c|c|c|c|}
\hline $\begin{array}{l}\text { Circuitos } \\
\text { Turísticos }\end{array}$ & Município pólo & $\begin{array}{l}\text { Quantidade de } \\
\text { municípios }\end{array}$ & Municípios integrantes \\
\hline Belo Horizonte & Belo Horizonte & 1 & Belo Horizonte \\
\hline Diamantes & Diamantina & 12 & $\begin{array}{l}\text { Alvorada de Minas, Couto de Magalhães de } \\
\text { Minas, Datas, Felício dos Santos, Gouveia, } \\
\text { Monjolos, Presidente Kubtischek, Santo Antônio } \\
\text { do Itambém, São Gonçalo do Rio Preto, Senador } \\
\text { Modestino Gonçalves; Serro. }\end{array}$ \\
\hline Grutas & Cordisburgo & 6 & $\begin{array}{l}\text { Capim Branco, Jequitibá, Lagoa Santa, } \\
\text { Matozinhos; Sete Lagoas. }\end{array}$ \\
\hline Guimarães Rosa & Morro da Garça & 8 & $\begin{array}{c}\text { Araçai, Buritizeiro, Corinto, Curvelo, Inimutaba, } \\
\text { Pirapora; Presidente Juscelino. }\end{array}$ \\
\hline Lago Três Marias & Três Marias & 9 & $\begin{array}{l}\text { Abaeté, Biquinhas, Felixlândia, Martino Campos, } \\
\text { Morada Nova de Minas, Paineiras, Pompeu, São } \\
\text { Gonçalo do Abaeté. }\end{array}$ \\
\hline Do ouro & Santa Bárbara & 17 & $\begin{array}{c}\text { Bom Jesus do Amparo, Caeté, Catas Altas, } \\
\text { Congonhas, Itabira, Itabirito, Mariana, Nova Era, } \\
\text { Nova Lima, Ouro Preto, Piranga, Raposos, Rio } \\
\text { Acima, Sabará, São Gonçalo do Rio Abaixo; } \\
\text { Santa Luzia. }\end{array}$ \\
\hline $\begin{array}{l}\text { Parque Nacional } \\
\text { da Serra do Cipó }\end{array}$ & Belo Horizonte & 6 & $\begin{array}{c}\text { Conceição do Mato Dentro, Congonhas do Norte, } \\
\text { Dom Joaquim, Jaboticatubas, Nova União, } \\
\text { Santana do Riacho }\end{array}$ \\
\hline $\begin{array}{l}\text { Verde - Trilha dos } \\
\text { Bandeirantes }\end{array}$ & Florestal & 8 & $\begin{array}{c}\text { Betim, Conceição do Pará, Esmeraldas, Juatuba, } \\
\text { Pitangui, Ribeirão das Neves, São Gonçalo do } \\
\text { Pará. }\end{array}$ \\
\hline $\begin{array}{l}\text { Trilha dos } \\
\text { Inconfidentes }\end{array}$ & São João Del-Rei & 20 & $\begin{array}{c}\text { Alfredo Vasconcelos, Antônio Carlos, } \\
\text { Barbacena, Barroso, Carrancas, Conceição da } \\
\text { Barra de Minas, Coronel Xavier Chaves, Dores } \\
\text { do Campo, Entre Rios de Minas, Ibituruna, } \\
\text { Lagoa Dourada, Madre de Deus de Minas, } \\
\text { Nazareno, Piedade do Rio Grande, Prados, } \\
\text { Resende Costa, Santa Cruz de Minas, São Tiago, } \\
\text { Tiradentes. }\end{array}$ \\
\hline $\begin{array}{l}\text { Veredas do } \\
\text { Brumadinho }\end{array}$ & Brumadinho & 6 & Betim, Belo Vale, Moeda, Rio Manso, Igarapé. \\
\hline $\begin{array}{l}\text { Villas e Fazendas } \\
\text { de Minas }\end{array}$ & $\begin{array}{l}\text { Conselheiro } \\
\text { Lafaiete }\end{array}$ & 9 & $\begin{array}{c}\text { Casa Grande, Catas Altas da Noruega, Cristiano } \\
\text { Otoni, Itaverava, Queluzito, Rio Espera, Santana } \\
\text { dos Montes, Senhora de Oliveira. }\end{array}$ \\
\hline
\end{tabular}

FONTE: ADAPTADO DA SECRETARIA DE TURISMO DO ESTADO DE MINAS GERAIS, 2012.

Foram enviados questionários por meio eletrônico para os gestores (necessariamente Turismólogos, de acordo com a legislação estadual) de cada CT 
durante o mês de fevereiro de 2011, cada um contendo 9 questões, sendo 3 delas relativas à identificação do gestor (faixa etária, gênero e escolaridade), 4 questões relativas à sua condição profissional (tempo de trabalho no $\mathrm{CT}$, inserção ex-ante em atividade do setor, treinamento recebido e auto-avaliação), 1 (uma) sobre a remuneração percebida e 1 (uma) relativa às principais dificuldades enfrentadas na gestão do CT.

A coleta e a tabulação dos dados foram realizadas nos meses de março e abril de 2011, embora quatro gestores não tenham respondido à solicitação de preenchimento sem qualquer justificativa.

\section{ANÁLISE E DISCUSSÃO DOS RESULTADOS}

Este tópico apresenta os resultados dos questionários aplicados junto aos gestores dos 11 (onze) circuitos turísticos da região central de Minas Gerais, dos quais 7 responderam.

Com o intuito de conhecer o perfil dos gestores dos circuitos, foram coletados os dados relativos a sexo, faixa etária, escolaridade e renda mensal. Verificou-se que 4 gestores que responderam aos questionários se situaram entre 31 a 38 anos e que 3 tinham entre 22 a 30 anos de idade, sinalizando que a gestão desses circuitos estava sob a direção de jovens profissionais, o que pode indicar para gestores mais atualizados no que se refere às novas tendências do turismo, embora não tragam um acúmulo considerável de experiência. Em relação ao sexo, 4 gestores que responderam aos questionários são do sexo feminino.

Quanto à escolaridade, 5 gestores contavam com mais de 15 anos de estudo e 2 dos gestores tinham de 12 a 15 anos de estudo. Dentre os gestores que responderam ao questionário, 3 haviam se dedicado mais de 5 anos de estudo relacionados ao turismo, número igual aos que dedicaram de 4 a 5 anos e apenas um mencionou ter de 1 a 3 anos de estudos ligados ao turismo.

Embora mais da metade dos respondentes já possuísse ou estivesse cursando pós-graduação, verificou-se que 4 deles estavam recebendo entre $R \$ 3.000,00$ e $R \$$ $9.000,00$ por ano. Isso pode refletir que as condições de sustentabilidade financeira do circuito sejam precárias ou até mesmo que o próprio profissional da área de turismo não 
esteja suficientemente valorizado, visto que apenas um deles recebia mais de $\mathrm{R} \$$ 12.000,00 por ano. Esse resultado coincide com os obtidos em outras pesquisas, conforme evidenciado no referencial teórico supracitado.

Em relação ao tempo de trabalho no CT, 2 gestores afirmaram estar trabalhando há menos de um ano e somente um trabalhava de um a dois anos. Então, como os 4 gestores restantes que trabalhavam há mais de dois anos na gestão dos CT's, seria importante uma maior aproximação entre esses dois "tipos" de gestores a fim de trocarem experiências e compartilharem informações acerca de suas atividades.

Todos os gestores que responderam ao questionário já haviam trabalhado no CT atual em outra função ou haviam tido experiência no setor de turismo, com destaque para o exercício de atividades do setor junto ao setor privado. Tal resultado é semelhante aos obtidos por Medaglia e Silveira (2010), onde 61\% dos egressos de cursos superiores em Turismo do Estado do Paraná estavam profissionalmente ligados à iniciativa privada.

Com relação ao conhecimento necessário para gerir o $\mathrm{CT}, 4$ gestores mencionaram se considerar muito bem preparados e 3 deles se consideravam bem preparados. Tal resultado condiz com o fato de todos já possuírem curso superior em Turismo e alguma experiência acumulada em atividades ligadas ao turismo.

Em relação ao treinamento para o desempenho de sua atividade, 4 gestores responderam que não haviam recebido treinamento específico para tal e os demais responderam que esse treinamento foi ministrado. Pelas respostas anteriores, onde uma grande parte dos gestores se considerava preparada para desempenhar suas funções, conclui-se que esse preparo adveio de sua própria experiência e de conhecimentos acumulados anteriormente e não como fruto de treinamento específico. Essa constatação poderia ser verificada pela Secretaria de Estado de Turismo de Minas Gerais (SETUR), já que a mesma é responsável por apoio técnico aos gestores dos CT's com reconhecimento oficial do governo.

Em relação às três principais dificuldades enfrentadas na gestão dos CT's, foram as mais apontadas pelos gestores, em ordem decrescente, a falta de apoio financeiro, de apoio político e de infraestrutura.

Talvez a falta de apoio financeiro como a principal dificuldade apontada pelos gestores possa ser superada principalmente por meio de sua sustentabilidade, ou seja, 
que o próprio CT gere seus recursos e não dependa de repasse financeiro dos órgãos públicos e municipais. Tal postura exigiria conhecimento e criatividade dos gestores, visto que novas formas de obtenção de recursos seriam implementadas, tais como selos de participação das empresas do setor privado, eventos e treinamentos, dentre outros.

Por outro lado, embora mais da metade dos gestores não tenham recebido treinamento específico para desenvolverem suas atividades, este item foi um dos menos apontados como uma das dificuldades enfrentadas.

Quanto à relação entre o $\mathrm{CT}$ e as Prefeituras dos municípios a que pertencem, 3 dos gestores que responderam às entrevistas mencionaram considerar que essa relação era ótima e 3 consideraram a relação boa, o que parece ser contraditório, visto que a falta de apoio político foi apontada como a segunda principal dificuldade enfrentada pelos gestores no circuito. Apenas um considerou regular a relação com as prefeituras.

\section{CONSIDERAÇÕES FINAIS}

É notório o crescimento da importância do turismo para muitas regiões brasileiras, que normalmente ocorre pela geração de emprego, renda, melhoria da autoestima da população local e, em muitos casos, pela preservação dos seus atrativos turísticos e do meio ambiente.

No Estado de Minas Gerais, desde 2003, a política utilizada para o desenvolvimento do setor foi a de reconhecer e certificar os circuitos turísticos existentes, o que significa, em tese, apoio político, técnico, financeiro e de pessoal ao circuito.

Mas vários circuitos enfrentam entraves para sua consolidação (GOMES et al. 2008). Na estrutura da associação responsável pelo circuito turístico, presidente e gestor desempenham as principais funções. Porém, como o gestor deve possuir o diploma de Bacharel em Turismo por força de Decreto-Lei de 2003, sua condição técnica o credencia a atuar de forma ampla nas atividades do circuito, exigindo-lhe, entretanto, conhecimentos de diversas outras áreas do conhecimento, tais como Administração, Economia, Contabilidade, Finanças, Logística, Estatística, dentre outras. 
Diante da importância do gestor, neste artigo - em pesquisa realizada junto a 7 gestores dos circuitos turísticos da região central - observou-se que, embora apresentem um perfil qualificado, tanto acadêmico quanto no mercado de trabalho - a questão salarial não acompanha tal qualificação.

Verificou-se também que embora o reconhecimento oficial do Estado tenha como uma de suas consequências um apoio técnico maior ao circuito, a maioria dos gestores entrevistados não recebeu nenhum treinamento para o exercício da função.

As principais dificuldades apontadas pelos gestores foram a falta de apoio financeiro, político e de infraestrutura, o que confirma resultados de trabalhos relacionados ao tema. Mesmo assim, para apenas um dos gestores a relação do CT com a prefeitura local foi considerada ruim.

Entende-se, portanto, que a consolidação dos circuitos turísticos implica em várias ações, tais como a criação das condições de sustentabilidade financeira, apoio político para as articulações necessárias junto às instituições governamentais, melhorias em termos de infraestrutura e, principalmente, maior valorização profissional do gestor do circuito turístico.

Em relação ao tipo de contato que um gestor possui com outros gestores de circuitos turísticos, evidenciou-se a falta de cooperação e de proximidade, ocorrendo apenas encontros esporádicos durante a realização de eventos ligados ao turismo, promovidos em nível estadual ou federal. Não existe uma organização em rede, onde os gestores possam trocar experiências e tomar decisões em conjunto, embora exista em Minas Gerais uma associação representativa de todos os circuitos turísticos, a FECITUR - Federação dos Circuitos Turísticos de Minas Gerais.

Para trabalhos futuros, recomenda-se que mais variáveis sejam avaliadas e que também se amplie a pesquisa aos demais gestores de circuitos turísticos de Minas Gerais. Essa extensão deve atingir os empresários e entes do setor público, no que diz respeito ao papel desempenhado pelo gestor do circuito, dado que esses podem contribuir com apoio pessoal, político e principalmente financeiro. Além disso, a questão relativa aos baixos salários auferidos pelos administradores de circuitos turísticos pode ser mais investigada.

Por fim, devem-se estabelecer alguns indicadores de sucesso de um CT para que, dentre outras possibilidades, seja associado o perfil do seu gestor à realidade porventura 
verificada nesses indicadores. Atualmente, o único "indicador" que existe para o "sucesso" de um circuito turístico é a renovação bienal do Certificado expedido pela Secretaria de Turismo do Estado de Minas Gerais, visto que se exige uma série de dados acerca da atividade turística - além de aspectos administrativos - inclusive demanda e oferta turística.

\section{REFERÊNCIAS}

BARBARÁ, S; LEITÃO, M. C. S; FONTES FILHO, J. R. A Governança Regional em Turismo: realidade? Estudo de caso sobre a Estrada Real. Cadernos EBAPE, v. 5, n. 4, p. 1-16, dez., 2007.

BENI, M. C. Globalização do turismo: megatendências do setor e a realidade brasileira. 2. ed. São Paulo: Aleph, 2003. (Série Turismo).

BIZ, A. A; CERETTA, F. Modelo de gerenciamento do fluxo de informação dos portais turísticos governamentais: uma abordagem teórica. Revista Turismo Visão e Ação Eletrônica, v. 10, n. 3, p. 399-414, set./dez., 2008.

BOLSON, J. H. G. Circuitos Turísticos de Minas Gerais - Modelo de Regionalização. Disponível em:

<http://www.revistaturismo.cidadeinternet.com.br?artigos/minasgerais.html>. Acesso em: 20/08/2006.

BREITNER, D.; CLEMENTS, C. H. J. Hospitality Management Curricula for the 21 Century. Hospitality and Tourism Educator, v. 8, n. 1, p. 57-60, 1996.

CZAJKOWSKI, A.; CUNHA, S. K. Organização e Coordenação da Rede de Cooperação em Aglomerados de Turismo Rural. Revista Turismo Visão e Ação Eletrônica, v. 12, n. 1, p. 92-113, jan./abr. 2010.

CHO, S.; WOODS, R. H.; JANG, S; ERDEM, M. Measuring the impact of human resource management practices on hospitality firms' performances. Hospitality Management, v. 25, n. 2, p. 262-277, 2006.

CÔRSO, I.; TRAVERSO, L. D.; ELESBÃO, I. A percepção dos gestores públicos em relação à divulgação e à promoção turística do município: uma análise no contexto da rota da amizade Convention \& Visitors Bureau, VIII SEMINÁRIO DA ASSOCIAÇÃO NACIONAL PESQUISA E PÓS-GRADUAÇÃO EM TURISMO, UNIVALI, Balneário Camboriú/SC, 02 e 04 de outubro de 2011.

DOMINGOS, M. C.; RIBEIRO, T. F. Uma Análise do Modelo de Gestão Regional do Turismo do Estado de Minas Gerais: O Caso do Circuito Grutas e Mar de Minas, V 
SEMINÁRIO DE PESQUISA EM TURISMO DO MERCOSUL - SEMINTUR. Universidade de Caxias do Sul, Caxias do Sul, 2008.

EMMENDOERFER, L. A Política Pública de Regionalização do Turismo em Minas Gerais: os circuitos turísticos. Turismo em Análise, v. 19, n. 2, ago., 2008.

EMMENDOERFER, L; BUENO E SILVA, L. F. T; EMMENDOERFER, M. L.; FONSECA, P. C. A formação dos circuitos turísticos mineiros: uma política pública descentralizada e democratizante? Observatório de Inovação do Turismo - Revista Acadêmica, v. 2, n. 4, dez., 2007.

FASENMAIER, D. R. Traveler Use of Visitor Information Centers: Implications for Development in Illinois, Journal of Travel Research, July, v. 33, n. 1, p. 44-50, 1994.

GLOBO. Profissionais de turismo questionam lei que não exige diploma. Disponível em: $\quad$ http://g1.globo.com/concursos-e-emprego/noticia/2012/01/profissionais-deturismo-questionam-lei-que-nao-exige-o-diploma.html>. Acesso em: 12/05/2012.

GOMES, B. M. A.; SILVA, V. J.; NETO, E. Q. A ação coletiva em regiões turísticas: um estudo dos circuitos turísticos de Minas Gerais, Turismo - Visão e ação, v. 8, n. 2, p. 332-330, 2006.

GOMES, B. M. A.; SILVA, V. J.; SANTOS, A. C. Políticas Públicas de Turismo: uma Análise dos Circuitos Turísticos de Minas Gerais sob a Concepção de Cluster. Turismo em Análise, v. 19, n. 2, ago., 2008.

HARRISON, J. S.; ENZ, C. A. Hospitality strategic management: concepts and cases. John Wiley \& Sons, Inc, Hoboken, N.J, 2005.

HUSELID, M. The impact of human resource management practices on turnover, productivity, and corporate financial performance, Academy of Management Journal, v. 38, n. 3, p. 635-672, 1995.

IBGE. Instituto Brasileiro de Geografia e Estatística. Censo demográfico 2010: caracterização da população e dos domicílios: resultado do universo. Rio de Janeiro, 2010.

LLOYD, R. Perceptions of employee turnover. Disponível em: <http://www.destinationkm.com/articles/default.asp?ArticleID=577>. Acesso em: 05/10/2000.

LÖFFLER, E. Governance: Die neue Generation von Staats - und Verwaltungsmodern-isierung. Verwaltung + Management, v. 7, n. 4, p. 212-215, 2001.

MEDAGLIA, J.; SILVEIRA, C. E. Reflexões sobre a atuação profissional dos turismólogos e o planejamento do turismo: pesquisa com os egressos dos Cursos de Turismo de Curitiba, Paraná, Brasil. Turismo \& Sociedade, Curitiba, v. 3, n. 2, p. 123 $146,2010$. 
MINAS GERAIS. Decreto n. 43.321 de 08 de maio de 2003. Dispõe sobre o reconhecimento dos Circuitos Turísticos e dá outras providências, Disponível em: <http://www.revistaturismo.com.br/artigos/minasgerais2.html>. Acesso em: 15/01/2010.

OLSEN, M. D. Literature in Strategic Management in the Hospitality Industry, International Journal of Hospitality Management, v. 23, n. 5, p. 411-424, 2004.

PÉREZ, E. A. Consideraciones em torno a los trabajos e investigaciones sobre calidad em la formación turística, Cuadernos de Turismo, n. 4, p. 7-19, 1999.

SANTOS, A. A. A importância do circuito turístico para o fomento da economia e da preservação ambiental - Caso "São Roque de Minas", Dissertação (Mestrado em Administração), Universidade Federal de Lavras, Lavras, Brasil, 2004.

SEBEN, R.; SILVA, T. F. da. Rede de cooperação entre pequenas empresas do setor turístico. Campo Grande, 2002. Disponível em:

<http://www.ba.agenciasebrae.com.br/download_anexo.kmf?cod=w8qgodnw47>.

Acesso em: 20/01/2009.

SECRETARIA DE ESTADO DE TURISMO (SETUR). Informações administrativas. Disponível em: <http://www.turismo.mg.gov.br/circuitos-turísticos/informaçõesadministrativas>. Acesso em: 09/09/2012.

SHELDON, P. J. The tourism information technology. Wallingford, UK: CAB International, 1997.

SILVA, T. F. da. Rede de cooperação entre pequenas empresas do setor turístico. Pasos: Revista de Turismo y Patrimonio Cultural. v. 2, n. 2, p. 267-279, 2004. Disponível em:

<http://www.pasosonline.org>. Acesso em: 23/05/2008.

SILVA, F. C. C; FABRIS, C. A atuação do turismólogo na sociedade da informação. 2008. Revista Digital de Biblioteconomia e Ciência da Informação, Campinas, v. 5 n. 1, p. 40-54, jan./jun. 2007.

SIMON, T.; HINKIN, T. The effect of employee turnover on hotel profits: A test across multiple hotels. Cornell Hotel and Restaurant Administration Quarterly, v. 42, n. 4, p. 65-69, 2001.

SOARES. C.; AMORIM, E. Cursos de Turismo: quantidade x qualidade - O caso de Salvador/ Bahia. Caderno Virtual de Turismo, v. 6, n.1, p. 49-58, 2006.

Recebido em: 28-08-2012.

Aprovado em: 28-09-2012. 